\title{
Ergonomic evaluation of workload by milk production - a bibliometric analysis
}

\author{
Claudilaine Caldas de Oliveira' ${ }^{1}$, Antônio Renato Pereira Moro', Leandra Ulbricht ${ }^{2}$, \\ Marjorie Belinelli², Gilberto F.M. de Souza ${ }^{3}$, Michele Gabriel', Izabel Cristina Zattar ${ }^{4}$ \\ ${ }^{1}$ Department of Production Engineering, Federal University of Santa Catarina, Campus Reitor João David Ferreira Lima, \\ SC, Florianópolis, Brazil \\ ${ }^{2}$ UTFPR - University Technological Federal of Paraná \\ ${ }^{3}$ USP - University of São Paulo \\ ${ }^{4}$ UFPR - University Federal of Paraná
}

Oliveira CC, Moro ARP, Ulbricht L, Belinelli M, Souza GFM, Gabriel M, Zattar IC. Ergonomic evaluation of workload by milk production a bibliometric analysis. Ann Agric Environ Med. 2017; 24(3): 376-382. doi: 10.26444/aaem/75505

\begin{abstract}
Introduction and Objective. The purpose of this study was to select in a structured manner the relevant articles with scientific recognition, and simultaneously identify the characteristics of these publications that may scientifically enrich the theme in a portfolio of papers. The theme involves ergonomics in milk production as a criterion for evaluating and improving organizational performance in the milking sector.

Materials and Method. The study used ProKnow-C as a theoretical instrument for intervention.

Results. The main results show: i) a bibliographic portfolio of 18 items aligned with the view adopted by researchers which served as a theoretical framework for this research; ii) The article entitled "Wrist positions and movements as possible risk factors during machine milking", by Marianne Stål, Gert-Åke Hansson and Ulrich Moritz in 1999 and published in the Journal of Applied Ergonomics presented the highest scientific recognition, iii) the authors highlighted in the bibliographic portfolio or in its references researching the subject are Gert-Åke Hansson, Marianne Stål and Stefan Pinzke, and iv) the International Journal of Industrial Ergonomics shows the highest number of scientific articles in the bibliographic portfolio.

Conclusions. The studies selected using the methodology indicate research in ergonomics focused on the production of milk in rural areas, specifically in the milking sector, are generally related to the health and safety of the workers.
\end{abstract}

\section{Key words}

milk production, ergonomics, dairy farming, work environment, bibliometric analysis

\section{INTRODUCTION}

Observations from several Brazilian studies have stressed the importance of dairy farming in the sustainability of farms, self-consumption, and especially in generating family income [1]. The dairy business, as in the other activities of the agricultural sector, has characteristics that are peculiar [2] which, if carried out in inappropriate situations, constitute potential risk to workers' health.

By its very nature, the science of ergonomics is a valuable analytical approach to human labour which can add important knowledge for agriculture and other activities in rural areas. In addition to its own development, the occupation allows a broad contribution to the design of new production systems and work organization for the evaluation and quality needed in order to incorporate the perspective of the health and comfort of workers involved in the activities [3].

Ergonomics is an autonomous discipline, but cannot exist without additionally acquiring various disciplines, dynamic acquisitions assimilated in an interdisciplinary spirit [4], characterized by gathering various fields of human knowledge to the advantage of workers. Ergonomics, the "science of work" [5], seeks ways for individuals to perform their work activities with more "safety, comfort and effectiveness" [4]. As a science, ergonomics is marked by socio-economic,

Address for correspondence: São Josafat, 2.221, Campo Mourão, PR 87.302-170 Brazil.

E-mail: claudilainecaldas@gmail.

Received: 27 April 2016; accepted: 9 May 2017; first published: June 2017 and especially technological changes, taking place in the labour market [6], and by its ergonomic operation, which attains a better perspective when inserted into organizational strategy [7].

However, most of the literature linked to the ergonomics of milk production is exclusively for the health and safety of workers, and it should also be included in the organization's planning cycles to ensure good business performance. Ergonomics actually studies the relationship between work organization and its milieu, by which workers' activities, work organization, the work conditions undertaken by the organization, such as methods, procedures, tools and its organization, are investigated $[8,9]$.

The presented study is focused on the search for answers to problems related to work organization in the production of Brazilian farmers' systems. Therefore, to investigate, reflect and assist, to map how ergonomics is linked to the dairy industry where the work is dictated by routine, is the challenge for future research.

since we cannot but engage deeply with all matters pertaining to human labor, whatever form it takes.

In the context of the dairy farm, ergonomics has emerged as being extremely useful, given the contribution of studies and research emphasizing the need for continuous change and improvement, both for production and the labour activity of farmers. The theme of ergonomics in milk production involves comprehensive and complex lines of research highlighting the difficulties in undertaking a study related to this subject. There is an additional difficulty related 
to the amplitude and dispersion of knowledge in various publications, editors, and databases. In this respect [10], the difficulty that many researchers face is justifying the selected theoretical framework to support their research activities. This situation indicates the importance of using a structured method that provides a consistent theoretical framework.

\section{OBJECTIVES}

Given these assumptions, the purpose of this study was to select, in a structured manner, relevant, scientifically recognized articles, and simultaneously identify the publication characteristics that may scientifically enrich the theme in a portfolio of papers, thus identifying the state of the art on the subject and approach possible gaps.

The objectives of the study were the selection of a relevant literature portfolio on the specified theme, conducting a bibliometric analysis of the selected bibliographic portfolio and its references; and attempting to identify the important articles, authors, and journals.

\section{MATERIALS AND METHOD}

The materials and method used for the development of the current investigation is subdivided into: i) methodology framework; and ii) intervention tool: Knowledge Development Process - Constructivist (ProKnow-C).

Methodology Framework. The study has an exploratorydescriptive character which is justified by the objective of the research - to acquire knowledge from research studies concerning the theme of ergonomics in milk production as a criterion for evaluating and improving the organizational performance in the milking sector. On the other hand, the descriptive character is justified by the evidence of the characteristics of such an area of knowledge [11].

The study is classified as theoretically-illustrative. For the technical procedures, the study uses bibliographic research, an analysis of scientific publications undertaken with contributions from different authors about the subject, with access permitted via CAPES ${ }^{1}$ - Coordenação de Aperfeiçoamento de Pessoal de Nivel Superior, which is recognized in both the academic and scientific domains in Brazil. The research also uses researchaction in which the researchers are involved in a cooperative and participant manner to solve the problem during the phase of adherence to the key words.

Intervention tool. Knowledge Development Process Constructivist (ProKnow-C). The knowledge construction process crucial for conducting a survey is unique in relation to the researcher and the boundaries imposed for the research. Also, the context within which the researcher is inserted, and the availability of access to the means of dissemination of research, influences this knowledge of the construction process [12].

As an intervention tool, the study used a literature review process called the Knowledge Development Process -

1. CAPES is a government agency linked to the Brazilian Ministry of Education in charge of promoting high standards for post-graduate courses in Brazil.
Constructivist (ProKnow-C), proposed by [13], which forms a constructivist perspective and shows a structured process to build the necessary knowledge on which the researcher can begin research on a specified subject. The ProKnow-C process consists of four phases (Fig. 1):

Phase 1: selection of the bibliographic portfolio (BP) of articles on the research subject; Phase 2: bibliometric analysis of the BP's;

Phase 3: systemic analysis of the BP;

Phase 4: identification of a research question and objectives for future researches $[14,10]$.

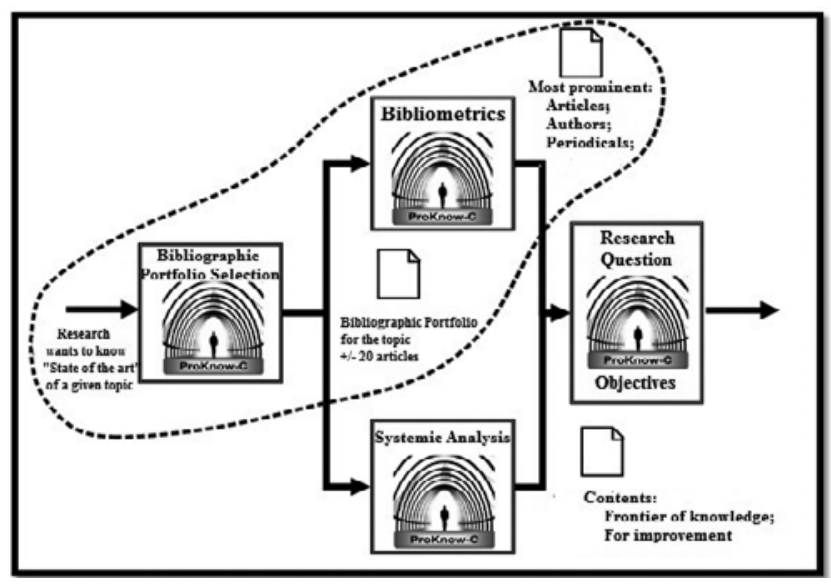

Figure 1. Knowledge Development Process - Constructivist (ProKnow-C): Process Stages

Source: Lacerda et al. (2012) [12]

In the current study, only the two first phases of the process were developed: selection of a portfolio of articles on the theme of the research subject, and the bibliometric analysis of the portfolio (Fig. 1). Hence, a part of the knowledge necessary about the research theme was constructed.

\section{RESULTS AND DISCUSSION}

Bibliographic Portfolio of the relevant scientific publications on the theme Ergonomics in milk production - milking sector. The Bibliographic Portfolio (BP) is a group of recognised specialist publications of scientific importance concerning specified theme assigned to the researchers. Selection of the BP resulted from a search made in the database of integrated periodicals using the fields: 'title', 'abstract' and 'key words', and based on the condition that the 'entire content' of each article is available free of charge. Scientific relevance is observed through the number of citations of the selected articles.

The sub-step Selection of the Bank of Raw Articles is the initial step in the process with the definition of the axels of the research, carried out according to the perception of the researchers. The first axel is intrinsically connected to the central theme of the Project, i.e. 'Ergonomics'. The second axel is connected with the focus 'Farm milk production'. After definition of the research, definition of the key words is transferred to each of the two axels: Axel 1 - Ergonomics - "human factor", "workload", "work analysis", "ergonomic work analysis", "work conditions", and "agricultural ergonomics" were defined. Axel 2 - Farm milk production - "dairy", "dairy farmers", "milking", and "milk production" 
were defined as key words. A combination of the key words from Axel 1 with those from Axel 2 was then carried out, which resulted in a total of 12 combinations.

Having defined the key words, identification of the database was through the articles for which the research was started. The criteria used for the selection of the database is that such a database should: i) be present in the Journal Portal CAPES - due to the availability of the researcher's access to this portal; ii) be in one of the following knowledge areas of CAPES considered to be relevant to the research, namely Engineering, Health Sciences, Agricultural Sciences and Multidisciplinary areas; iii) have tools that avail the possibility of research in the fields: title, abstract and key words; iv) make the search tool available with the possibility of using boolean expressions; v) have the availability to establish a temporal horizon of search; vi) have the availability to select the type of publication (only of the type 'Journal Article'); and, vii) have the feedback of the lowest number of results in the search, at least one scientific article.

Initially, 15 databases were identified: Academic Search Premier-ASP (EBSCO), Annual Reviews, Cambridge Journals Online, Compendex (Engineering Village 2), Emerald Fulltext (Emerald), Gopubmed, IEEE Xplore, Technology Research Database (ProQuest), Publmed, SAGE Journals Online, SCIELO, Science Direct (Elsevier), SCOPUS (Elsevier), Web of Science e Wiley Online Library. Of these, nine databases met these criteria Initially, 15 databases were identified: Academic Search Premier - ASP (EBSCO), Annual Reviews, Cambridge Journals Online, Compendex (Engineering Village
2), Emerald Fulltext (Emerald), Gopubmed, IEEE Xplore, Technology Research Database (ProQuest), Publmed, SAGE Journals Online, SCIELO, Science Direct (Elsevier), SCOPUS (Elsevier), Web of Science e Wiley Online Library. Of these, nine databases met these criteria: Scopus, ISI Web Of Knowledge, Engineering Village, Science Direct, Proquest, Ebsco, IEEE, Wiley and Pubmed, and were selected: Scopus, ISI Web Of Knowledge, Engineering Village, Science Direct, Proquest, Ebsco, IEEE, Wiley and Pubmed, and were then selected.

The selection step of the article set had 1,862 publications, which were included in the initial portfolio called Gross Article Bank and went through successive filters to obtain a more comprehensive result of the research objectives. A time limit was set restricting the temporal space of articles published: 1970-2015. In order to collect the studies and compile the Article Bank, downloading into an EndNote ${ }^{\circledast}$ X6 library was used as a bibliographic manager and for exporting metadata.

The sub-step filtering of the Bank of Raw Articles using the bibliographic manager, the filtration of the gross articles bank, as identified in the databases, was conducted. A total of 1,862 publications were analysed and the following aspects taken into considered: i) presence of repeated/redundant articles; ii) alignment of article titles with the topic; iii) scientific recognition of the articles; iv) alignment of abstracts with topic; and v) availability of the complete articles in the databases. Examination of the articles resulted in 18 meeting the inclusion criteria. Thus, the Bibliographic Portfolio consisted of 18 articles (Tab. 1).

Table 1. Articles that comprises Bibliographic Portfolio

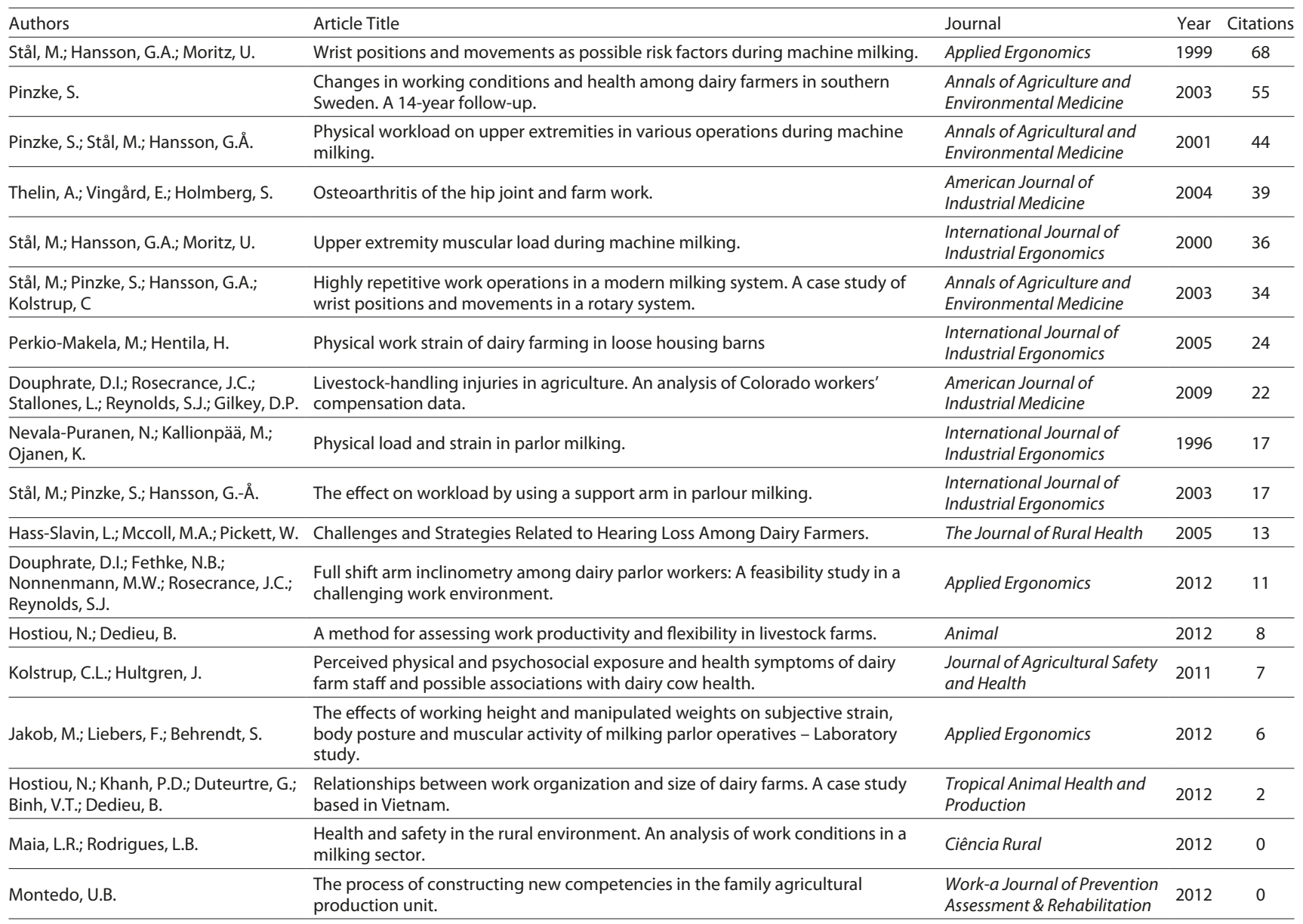


In order to carry out analysis, scientific recognition was assessed according to the citations in other scientific works since publication, all the tools were consulted through the tool Google Scholar to identify the number of article citations and arranged in decreasing order.

The sub-step test of Representativeness was performed to analyze the cited bibliographic references in the articles forming Bibliographic Portfolio (BP). In order to facilitate the composition of the references of the articles of the BP, all references in the articles were surveyed and restricted to articles published in journals, the EndNote ${ }^{\oplus}$ X library was used one more time, and a new query was performed in Google Scholar concerning the number of article citations from the BP.

Subsequently, the spreadsheet was reorganized and arranged in decreasing order, aimed at the inclusion of articles that are aligned and have scientific representation, but for some reason are not in the BP, while all the articles identified were already in the Bibliographic Portfolio. Thus, as a result, this step did not identify other articles aligned with the theme in the references of the BP.

Bibliometric Analysis. The next step was the Bibliometric Analysis of the 18 articles of the BP (Tab. 1). This step consisted of applying statistical methods to the selected articles, to quantify the existing information: i) recognition of scientific articles; ii) who is (are) the researcher(s) with a trajectory in this area of knowledge; and, iii) which journals have space devoted to the subject of ergonomics in milk production - milking sector).

Figure 2 shows the evolution of publications over the years and the growth trends that from 2001 peaked in 2003, 2005 and 2012, and in 1996, 1999, 2000, 2001, 2004, 2009 and 2011, when distribution remained constant.

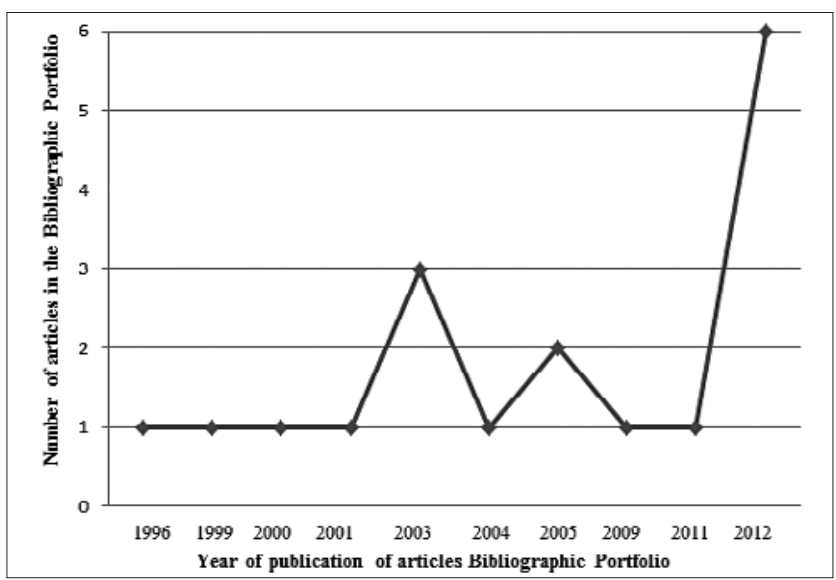

Figure 2. Evolution of scientific production - Bibliographic Portfolio (BP)

Scientific recognition of articles in the Bibliographic Portfolio (BP). The scientific recognition of Articles in the Bibliographic Portfolio (BP) was defined by the number of times the article has been quoted in other scientific articles, as identified by using Google Scholar. (Tab. 1). This was important for seeking research accepted by the academic and scientific community.

Figure 3 highlights the 18 articles in the BP, with their respective codes for overall scientific recognition. The article entitled "Wrist positions and movements of the possible risk factors during machine milking” by Marianne Stål, Gert-Åke
Hansson and Ulrich Moritz in 1999 and published in Applied Ergonomics, recieved the highest scientific recognition, being cited 68 times by other scientific articles by May 2014, the date of the survey. Thes study shows that the activities concerning milking require workers' positions and movements that may result in injuries to the wrists and hands. This confirms the high prevalence of symptoms of musculoskeletal disorders, since high values were found loaded in the upper extremities that increased with respect to dorsiflexed hand position and repetitiveness when milking in the modern loose-housing system. Thus, the speed and repeatability of these activities was close to the values reported with repetitive work movements and with a high risk of disturbances in the elbows and hands, which may lead to an increased risk of carpal tunnel syndrome.

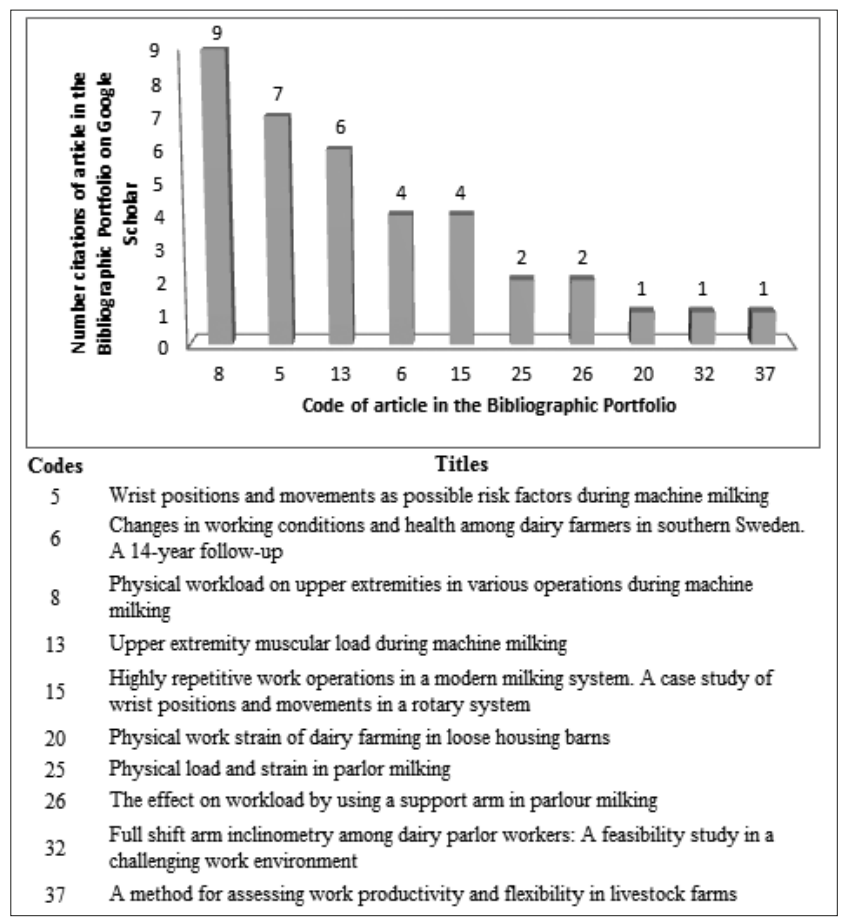

Figure 3. Relevance of BP articles

Also noteworthy (Fig. 3), the article "Changes in working conditions and health among dairy farmers in southern Sweden, A 14-year follow-up" [15] with 55 citations, describes and analyzes the changing health and work among dairy farmers in Scania, southern Sweden, during 1988-2002. The biggest significant changes were increases in the symptoms of pain in the shoulder, neck and wrists/hands. The most common and persistent symptoms reported involved the shoulder. The presence of stress and lack of time for leisure activities were also perceived as factors that could also influence the prevalence of musculoskeletal symptoms and the quality of life of the workers. Thus, strategies for prevention and intervention measures should be considered as physical factors at the workplace, as well as the personal characteristics and lifestyle of dairy farmers [15].

An article by Stefan Pinzke, Marianne Stål and Gert-Åke Hansson, "Physical work load on upper extremities in various operations during machine milking", published in 2001 in Annals of Agricultural and Environmental Medicine was cited 44 times. It quantified the load in the upper extremities (arms, wrists and hands) of the workers' body during the 
execution of milking activity and, like other authors, affirm that muscle high loads in combination with extreme positions and movements of hands and forearms may contribute to the development of lesions among milkers. The results of this study demonstrate the need for technical improvements in equipment, in addition to the need to develop technical devices to facilitate the milking operation. Thus, more research is needed on dairy farms, both to reduce the risk of injuries to wrists, hands and arms.

In the current study, another analysis at this stage was to identify the relevance of BP items in articles referred to in the BP. Among the 18 articles of the BP, 10 were referenced, i.e. $55.5 \%$ of BP items are recognized by researchers of the subject. Of these, the article with the most relevance, i.e. with nine quotations from BP items, was the article "Physical workload on upper extremities in various operations during machine milking" [16], followed by the article "Wrist positions and movements of the possible risk factors during machine milking" [17], with seven quotes. It is noteworthy that this article also had the highest scientific recognition. Another article by the same author, which was also the third most relevant article with six citations in the references of the BP, "Upper muscle extremity load during machine milking" [18], quantified muscle load on the upper extremities (upper body) of 11 workers who performed the milking activity. The study aimed sat understanding the etiology of musculoskeletal problems in the forearm and hand, while simultaneously focusing attention on the involvement of the nerves.

Thus, research into two different production systems (milking) was undertaken: the mechanical milking system with a bucket at the bottom and the milking machine connected to milk ducts, in which the milking parlour had a gap (floor difference between the worker and the animal to be milked). The results showed high peak loads in the flexor and extensor muscles which, in combination with the position and movements of the hand and forearm, can contribute to the development of injuries to the wrists and hands. The difference in the milking system supports the peak load of the upper extremities, but at the mechanical bucket at the foot system, there is an increased static charge that reduces muscle relaxation with respect to the system linked to the milk ducts.

For the milking activity, the authors suggest that these negative effects should be considered during the construction of new milking systems, and further studies are needed to investigate this supposed mechanism. Development of new techniques are needed to reduce the prevalence of workrelated diseases.

The most relevant articles selected by the presented methodology emphasize aspects related to the theme involving ergonomics in the milk production - milking sector. Thus, the BP articles showed diverse purposes, among them, 72.22\% assessed the ergonomic risks in the musculoskeletal system, especially concerning the upper body during the execution of milking activity, i.e. the physical workload. Some of these articles have investigated further the prevalence of Workrelated Musculoskeletal Disorders (WMSD), and diseases such as osteoarthritis of the hip joint. Other articles found work scenarios in the milk production, such as the organizational conditions, obtaining new skills, challenges and strategies with milk producers who have hearing loss, determine the costs, consequences and factors associated with absence from work due to wound management activity with cattle.
Highlighted authors. The purpose of this sub-step is to identify the existence of authors with a trajectory in research on ergonomics in milk production. This information is relevant because it indicates who the authors dedicate themselves to the topic, and whose previous scientific studies should be searched for a better comprehension and update of knowledge about the theme (Fig. 4).

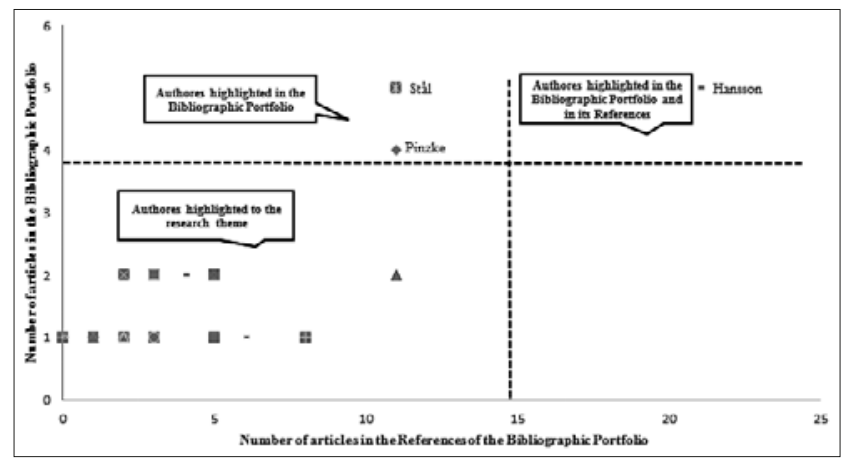

Figure 4. Highlighted Authors on $\mathrm{BP}$

As a result, the following authors were identified: Hansson (five articles), Stål (five articles); Pinzke (four articles); Dedieu; Douphrate; Hostiou.; Kolstrup; Moritz; Reynolds; Rosecrance (two items each), They stood out from among the others highlighted because they had produced more articles in the bibliographic portfolio and were mentioned in the bibliographic references. Other authors participated with just one article. The following authors can also be highlighted in the bibliographic portfolio: Marianne Stål with five studies and Stefan Pinzke with four. These authors can be identified with their greater participation in the Library Portfolio, references: Gert-Åke Hansson, associate professor in the Department of Occupational and Environmental Medicine, University of Lund, Sweden, in partnership with Marianne Stål and Stefan Pinzke, lecturers at Department of Agricultural Biosystems and Tencnology at the Swedish University of Agricultural Sciences (Alnarp campus), Sweden. They have developed several studies with ergonomics in agricultural units for the production of bovine milk

A total of 871 to 363 author jobs were referenced by the portfolio of research articles. Thus, the authors highlight Hansson was cited 21 times; Skerfving cited 12 times; Dedieu, Ohlsson, Stål, Pinzke and Akeson cited 11 times; Balogh (10); Mathiassen (9); and Thelin (8). These authors have great reference in the area of ergonomics, focusing on farms with a dairy farm.

Highlighted journals. Among the 18 publications in the Bibliographic Portfolio (BP), published in 10 different journals, the presented study will list the journals that devoted to the publication of the specified subject (Fig. 5).

As shown in Figure 5, the International Journal of Industrial Ergonomics was the most highlighted journal, with four of the articles in the BP, followed by Applied Ergonomics and Annals of Agricultural and Environmental Medicine, with three publications, respectively. The other journals contributed two publications, and were mentioned in the references, and the American Journal of Industrial - two articles.

The relevance of the theme for the BP was based on the analysis of the impact factor of the journals, extracted from the Scopus database (SJR) and ISI Web Knowledge (JCR). 


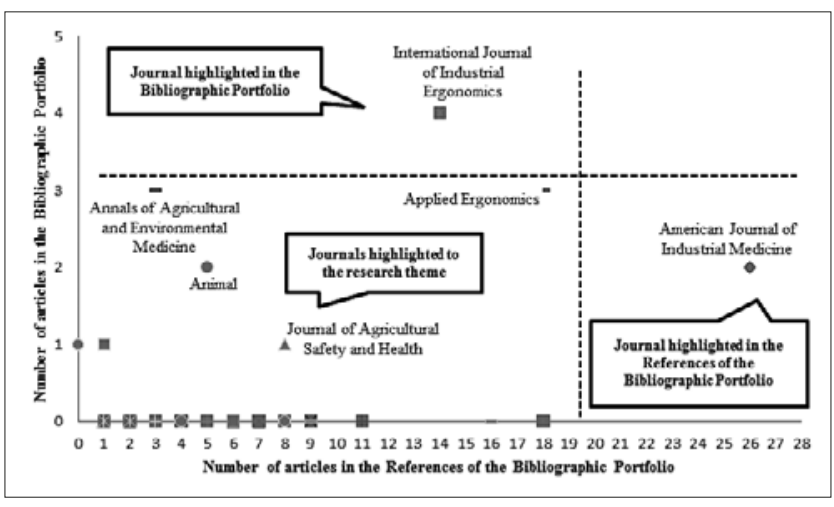

Figure 5. Relevance of the journals in the BP

The calculation of the impact factor allowed identification of journals in which articles published in it showed the most frequently mentioned citations.

The results of the SJR (Fig. 6) show that the periodical of BP items with the high impact factor is Applied Ergonomics. From this analysis, it can be see that between the lowest and highest SJR, the range is $43.28 \%$, showing that for the set BP, periodicals feature SJR with average growth.

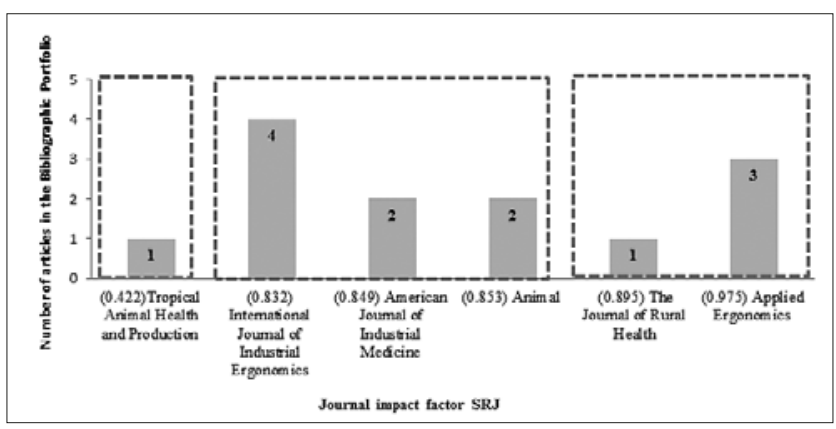

Figure 6. Impact Factor of Periodical Bibliographic Portfolio (SJR)

To calculate the JCR impact factor, journals that were not indexed in ISI Web Knowledge base were excluded (Fig. 7).

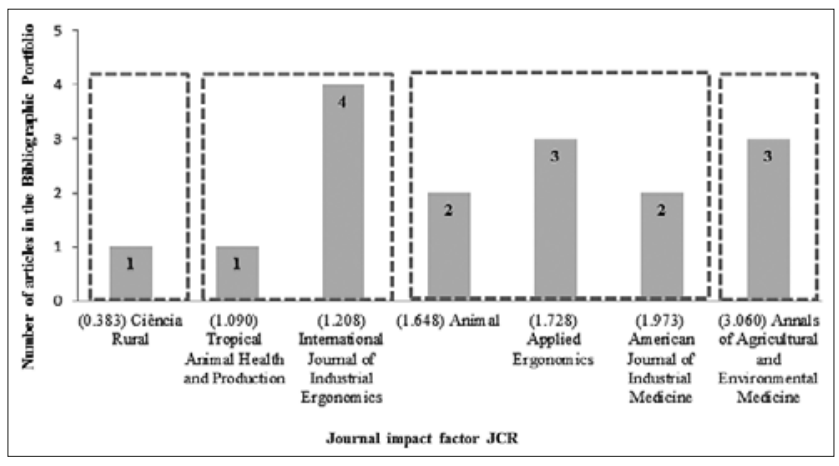

Figure 7. Relevance of the article in the journal of Library Portfolio (JCR)

Figure 7 shows that all journals had an impact factor greater than 1 (one), with the exception of Periodical Rural Science. The journals with high impact factor were: Annals of Agricultural and Environmental Medicine (3,060), American Journal of Industrial Medicine (1,973), Applied Ergonomics $(1,728)$ and Animal $(1,648)$.

The relevance analysis of the journals in BP references identified a number of articles published in each journal. At this stage, it analyzed 363 works, cited as references by the 18 articles of the BP.

A total of 148 journals were identified in the works referenced by Articles BP; the most cited were: American Journal of Industrial Medicine (26), Ergonomics and Applied Ergonomics (18), Scandinavian Journal of Work, Environment \& Health (16), International Journal of Industrial Ergonomics (14), Journal of Dairy Science (11), Agricultural Systems and Occupational Medicine (9), Journal of Agricultural Safety and Health, and Journal of Occupational and Environmental Medicine (8), respectively; as well as Acta Orthopaedica Scandinavica and Journal of Agromedicine (7), among others. However, it appears that the theme was published in journals covering different areas, thus highlighting the multidisciplinary nature of the theme.

From the analysis, it was possible to infer that the most prominent journals in the Library Portfolio and references regarding the subject of the research are the International Journal of Industrial Ergonomics and Applied Ergonomics. This result is justified by the editorial line taken by the magazines, focused on the application of ergonomics in the design, planning and management of production, technical and social systems in the workplace, especially in the rural sector that that involves milking activities, and a clear relationship with the subject under study.

\section{CONCLUSIONS}

The presented Bibliometric Analysis is based on the cumulative findings of 18 publications with academic relevance ranking and conducted from the perspective of the number of citations. The most cited author(s) in the bibliographical references of articles selected in the portfolio work who stood out were Marianne Stål, Gert-Åke Hansson and Ulrich Moritz for their aticle "Wrist positions movement and the possible risk factors during machine milking", published in 1999 in the Journal of Applied Ergonomics, which was the principal journal dealing with and publishing on the subject in question They were also the featured authors. As for in relation to relevant authors researching on the themes of researchers

The scientific production found in the bibliographic portfolio has shown the theme that involves ergonomics in milk production exclusively for the health and safety of workers, but this should also be added to the organization planning to ensure good business performance.

This study conducted an investigation to identify the relevant publications dealing with ergonomics in milk production as a criterion for evaluating and improving organizational performance in the milking sector, as reported by the ProKnow-C intervention instrument. From this knowledge of the bibliographic portfolio and identification of the characteristics of this portfolio, the following future researches are suggested: i) continuation of this research with the development of systemic analysis and identification of opportunities for research through ProKnow-C.

\section{REFERENCES}

1. Ulbricht L, Stadnik AM. Identificação dos Fatores de Risco Presentes na Ordenha: Aplicação no Estudo dos Distúrbios Osteomusculares 
Relacionados ao Trabalho dos Ordenhadores no Paraná. In: ENEGEP - XXX Encontro Nacional de Engenharia de Produção, São Carlos. Anais... São Carlos: ABEPRO, 2010.

2. Santos Filho JC. Flexibilidade na organização do trabalho em sistemas de produção de leite no norte do Paraná - Brasil e no departamento de La Loire - França. (Mestrado em Zootecnia) - Programa de PósGraduação em Zootecnia, Universidade Estadual de Maringá, 2012.

3. Gemma SFB. Complexidade e agricultura: organização e análise ergonômica do trabalho na agricultura orgânica. (Doutorado em Engenharia Agrícola) - Universidade Estadual de Campinas, 2008.

4. Wisner A. Questões epistemológicas em Ergonomia e em análise do trabalho. In: Daniellou, F. A. Ergonomia em busca de seus princípios: debates epistemológicos. São Paulo: Edgar Blücher, 2004; 29-56.

5. Montmollin M. A ergonomia. Lisboa: Instituto Piaget, 1990.

6. Hendrick HW. Determining the cost-benefits of ergonomics projects and factors that lead to their success. Appl Ergon. 2003; 34(5): 419-427.

7. Vidal MC. Ergonomia na empresa: útil, prática e aplicada. 2.ed. Rio de Janeiro: Editora Virtual Científica, 2002.

8. Zamboni J, Barros MEB. Micropolítica da atividade. Barbarói (UNISC. Online), 2012; 36: 113-137.

9. Montmollin M, Darses F. A Ergonomia. 2. ed. (aumentada e revisada). Porto Alegre, 2011.
10. Tasca JE, Ensslin L, Ensslin SR, Alves MBM. An approach for selecting a theoretical framework for the evaluation of training programs. J Eur Ind Trai. 2010; 34(7): 631-655.

11. Vergara SC. Projetos e relatórios de pesquisa em Administração. 9. ed. São Paulo: Atlas, 2007.

12. Lacerda RTO, Ensslin L, Ensslin SR. Uma análise bibliométrica da literatura sobre estratégia e avaliação de desempenho. Gest Prod. 2012; 19(1): 59-78.

13. Ensslin L, Ensslin SR, Pinto HM. Processo de investigação e análise bibliométrica: avaliação da qualidade dos serviços bancários. RAC. 2013; 17(3): 325-349.

14. Rosa FS, Ensslin SR, Ensslin L, Lunkes RJ. Management environmental disclosure: a constructivist case. Manag Decis. 2012; 50(6): 1117-1136.

15. Pinzke $S$. Changes in working conditions and health among dairy farmers in southern Sweden. A 14-year follow-up. Ann Agric Environ Med. 2003; 10(2): 185-195.

16. Pinzke S, Stål M, Hansson GÅ. Physical workload on upper extremities in various operations during machine milking. Ann Agric Environ Med. 2001; 8: 63-70.

17. Stål M, Hansson GA, Moritz U. Wrist positions and movements as possible risk factors during machine milking. Appl Ergon. 1999; 30(6): 527-533.

18. Stål M, Hansson GA, Moritz U. Upper extremity muscular load during machine milking. Int J Ind Ergon. 2000; 26: 9-17. 